\title{
Estimation of daily dietary fluoride intake: 3-d food diary v. 2-d duplicate plate
}

\author{
N. Omid ${ }^{1}$, A. Maguire ${ }^{2}$, W. T. O'Hare ${ }^{3}$ and F. V. Zohoori ${ }^{1 *}$ \\ ${ }^{1}$ Health and Social Care Institute, Teesside University, TS1 3BA, UK \\ ${ }^{2}$ Centre for Oral Health Research, Newcastle University, NE2 4BW, UK \\ ${ }^{3}$ School of Science and Engineering, Teesside University, TS1 3BA, UK \\ (Submitted 11 March 2015 - Final revision received 5 June 2015 - Accepted 2 September 2015- First published online 6 October 2015)
}

\section{Abstract}

The 3-d food diary method (3-d FD) or the 2-d duplicate plate (2-d DP) method have been used to measure dietary fluoride (F) intake by many studies. This study aimed to compare daily dietary F intake (DDFI) estimated by the 3-d FD and 2-d DP methods at group and individual levels. Dietary data for sixty-one healthy children aged 4-6 years were collected using 3-d FD and 2-d DP methods with a 1-week gap between each collection. Food diary data were analysed for F using the Weighed Intake Analysis Software Package, whereas duplicate diets were analysed by an acid diffusion method using an $\mathrm{F}$ ion-selective electrode. Paired $t$ test and linear regression were used to compare dietary data at the group and individual levels, respectively. At the group level, mean DDFI was 0.025 (sD 0.016) and 0.028 (sD 0.013) mg/kg body weight (bw) per d estimated by 3-d FD and 2-d DP, respectively. No statistically significant difference $(P=0 \cdot 10)$ was observed in estimated DDFI by each method at the group level. At an individual level, the agreement in estimating F intake ( $\mathrm{mg} / \mathrm{kg}$ bw per $\mathrm{d}$ ) using the 3-d FD method compared with the 2-d DP method was within \pm 0.011 (95\% CI 0.009, 0.013) $\mathrm{mg} / \mathrm{kg}$ bw per $\mathrm{d}$. At the group level, DDFI data obtained by either the 2-d DP method or the 3-d FD method can be replaced. At an individual level, the typical error and the narrow margin between optimal and excessive F intake suggested that the DDFI data obtained by one method cannot replace the dietary data estimated from the other method.

\section{Key words: Fluoride: Diet: Food diaries: Duplicate plate collection}

Fluoride (F) has an important nutritional and public health impact due to its beneficial role in mineralisation of bones and teeth ${ }^{(1)}$. Following gastrointestinal absorption, $\mathrm{F}$ is mainly incorporated into calcified tissues that contain $>99 \%$ of body burden of $\mathrm{F}$. The role of $\mathrm{F}$ in improving oral health by providing a protective effect against dental caries is well established ${ }^{(2,3)}$. However, excessive $\mathrm{F}$ intake during tooth development can increase the risk of dental fluorosis (tooth mottling). The optimal total daily intake of $\mathrm{F}$ to benefit dental health, while minimising the risk of developing dental fluorosis, has been suggested to range between 0.05 and $0.07 \mathrm{mg} / \mathrm{kg}$ body weight (bw) per $\mathrm{d}^{(4)}$, whereas an intake of $0.1 \mathrm{mg} / \mathrm{kg}$ bw per $\mathrm{d}$ has been termed as the tolerable upper intake level (UL) ${ }^{(5)}$ - the level at which moderate forms of dental fluorosis can develop. Due to the narrow margin between optimal and excessive $\mathrm{F}$ intake, knowledge of total daily F intake (TDFI) at the individual and population level is essential when recommendations for $\mathrm{F}$ use, particularly in young children, are being considered.

The common sources of systemic F are diet and toothpaste. According to the literature, the reported contribution of diet to TDFI ranges from $20 \%$ in 1-3-year-old Brazilian children ${ }^{(6)}$ to $75 \%$ in 6-year-old children living in an optimally fluoridated area in the $\mathrm{USA}^{(7)}$. Such variations could be due to the differences in age, tooth brushing, dietary habits and F concentration of the diet as well as the dietary methods used to assess dietary $\mathrm{F}$ intake in these groups of children.

In a group of 6-7-year-old UK children, diet has been reported to contribute between 44 and $41 \%$ of TDFI to those living in a low $\mathrm{F}$ area $(0.30 \mathrm{mgF} / \mathrm{l})$ and natural $\mathrm{F}$ area $(1.06 \mathrm{mgF} / \mathrm{l})$, respectively $^{(8)}$. Tap water, fruit squashes (prepared with tap water) as well as cooked rice, pasta and vegetables were reported as the main sources of dietary $\mathrm{F}$ intake in 6-7-year-old children receiving optimally fluoridated water $(0.82 \mathrm{mgF} / \mathrm{l})$, whereas carbonated soft drinks and bread were the most important contributors to dietary $\mathrm{F}$ intake in those children receiving non-fluoridated water $(0.08 \mathrm{mgF} / \mathrm{l})^{(9)}$.

Depending on the purpose of the evaluation, different methods have been used to assess dietary intake of energy and nutrients, with a 7-d weighed food diary regarded frequently as the 'gold standard' method ${ }^{(10)}$. However, the two most commonly used dietary assessment methods for daily dietary $\mathrm{F}$ intake (DDFI) are duplicate plate and food diary methods. Although the food diary method estimates $F$ intake on the basis of Food Composition Tables, the actual foods and drinks collected in duplicate diets are analysed for $\mathrm{F}$ when a duplicate plate method is used. However, both methods have

Abbreviations: 2-d DP, 2-d duplicate plate; 3-d FD, 3-d food diary; bw, body weight; DDFI, daily dietary F intake; F, fluoride.

* Corresponding author: Professor F. V. Zohoori, fax +44 1642 342770, email v.zohoori@tees.ac.uk 
drawbacks, which may limit their use in some populations. Due to $\mathrm{F}$ analysis of the duplicated diets, this method is suggested to reflect the actual $\mathrm{F}$ content of the diet ${ }^{(11)}$. However, this estimate might be affected by reporting bias if any food or drink items are omitted from the duplicate. In addition, as all the food and drinks are pooled, the primary food or drink sources of dietary $\mathrm{F}$ intake cannot be identified. In contrast, using the food diary method, a full description is provided for consumed food and drinks, allowing individual sources of $\mathrm{F}$ intake to be identified $^{(12)}$. Furthermore, if food and drinks are recorded at the time of consumption, the measurement is less likely to be affected by misreporting. The food diary method is also less burdensome for participants, and therefore more practical for use with large numbers of study subjects. However, the food diary method may also be affected by coding errors and/or non-inclusion of a given food type in the Food Composition Table ${ }^{(13)}$. The major burden of the duplicate plate collection is the cost, which may result in individuals altering their dietary habits. Although the cost of duplicating is usually reimbursed to participants, applying this method to large-scale epidemiological studies can be very costly and may result in a lower response rate $e^{(10,14)}$.

Regular monitoring of $\mathrm{F}$ intake in children has been suggested by the $\mathrm{WHO}^{(15,16)}$. To maximise prevention of dental caries and minimise the risk of dental fluorosis, assessment of $\mathrm{F}$ intake at both an individual and a community level is crucial before making any decision on $\mathrm{F}$ use or $\mathrm{F}$ supplementation.

No robust evidence is available to suggest the use of one method over another for the assessment of dietary $\mathrm{F}$ intake, although the choice is dependent on the aims and objectives of a given study - for example, to identify the main dietary sources of $\mathrm{F}$ or to provide baseline data for public health administrators when determining whether any additional fluoridisation programme for caries prevention is needed.

There is only one pilot study in the literature that has reported dietary $\mathrm{F}$ intake estimated by both duplicate plate and food diary methods in a group of 15-30-month-old children living in an area with fluoridated water supply in Indiana, USA ${ }^{(17)}$. However, the major limitation of that study was the small sample size ( $n$ 12), all of whom were recruited from a single day-care centre. Furthermore, findings from one population and in a particular setting can be limited in terms of representativeness and potential for extrapolation, and therefore additional research in different populations and settings is warranted. Therefore, the aim of this present study was to compare DDFI, at group and individual levels, estimated by the following two methods: '2-d duplicate plate (2-d DP)' and '3-d food diary (3-d FD)'. The subsidiary aims were to compare daily variation in dietary $\mathrm{F}$ intake at the individual level obtained by each method.

\section{Methods}

This study was conducted according to the guidelines laid down in the Declaration of Helsinki. All the procedures involving human subjects were approved by the County Durham and Tees Valley I Research Ethics Committee (Ethics no. 08/H0905/116). Written informed consent was obtained from all the participants before the study was initiated.
The study was undertaken in Newcastle upon Tyne, a city located in the north-east of England with the tap water supply fluoridated at $0.9 \mathrm{ppm}$. Before the study was initiated, the Director of the Children's Service Directorate and Local Education Authorities were contacted and informed of the study. Parents of all healthy children aged 4-6 years were contacted through the primary schools, which agreed to take part in the study. In total, sixty-one parental consents were obtained.

The study had a randomised cross-over design, comparing observations within and between individuals. Each child underwent two data and sample collection sessions in which a different dietary method was used, with an interval of approximately 1 week between each session. Children were randomised to the order in which the two allocated dietary methods were used and each family was visited three times at home between April and November 2009 to collect samples and data.

During Visit 1, the weight of child was measured without shoes and jacket to the nearest $0.1 \mathrm{~kg}$ using a portable digital balance (Soehnle Linea; ADE GmbH \& Co.). Height was also measured to the nearest $0 \cdot 1 \mathrm{~cm}$ using a stadiometer (Soehnle MZ10020; ADE GmbH \& Co.). Parents were provided with collection containers and bottles as well as written instructions for collecting duplicated meals and verbal instructions for sample collection. A sample of tap water was collected at each visit and dietary data were collected during the second and third visits. The importance of maintaining the usual dietary habits during the dietary data collection period was emphasised to the parents.

\section{Dietary data collection}

3-d food diary method. A food diary, with complete instructions on how to record food/drink items, was given to parents. They were also instructed verbally on how to estimate serving portion sizes using common everyday household items ${ }^{(9,12,18)}$. They were asked to take the food diary with them anywhere they went outside the home and record all the food items and drinks consumed by their child over 3 consecutive days, comprising 2 weekdays and 1 weekend day. During weekdays, if the child took a packed lunch to school, food and drinks included in the packed lunch were recorded by the parents. Parents were asked to remind their child to bring back any leftovers in order for them to record the correct amount of consumed food. However, if the child was receiving a school dinner, the study researcher attended the school to record the items. In addition, for each home-made food and drink consumed, parents were requested to keep a sample of approximately $50 \mathrm{~g}$ in a plastic storage container provided for this purpose and record the recipe in the food diary. During weekdays, the study researcher visited the school to record the items consumed by each study child. A post-completion interview with parents was conducted on Day 4 (Visit 2) to ensure that all dietary data had been recorded as precisely as possible. The accuracy of estimates of food portion sizes made by parents was also checked using a photographic food atlas ${ }^{(19)}$.

2-d duplicate plate method. Parents were asked to duplicate portions of all food and drink items consumed by their child by 
carefully observing and replicating the actual consumed amounts over 2 consecutive days - 1 weekday and 1 weekend day ${ }^{(11,20)}$. Parents were provided with (1) storage containers for duplicated food, (2) storage bottles for duplicated water and (3) storage bottles for other duplicated drinks and were instructed to separate the parts of food items not usually eaten such as bones, fruit skin, cores, etc., before placing them in the provided container, keeping containers for each day separate. During the school days, an identical duplicate of each child's school dinner as well as any other consumed items such as midday snack was obtained from the school by the researcher.

At the post-completion interview, which was conducted on Day 3 (Visit 3), all the duplicate items were checked with parents to ensure that no food and drinks had been omitted from the duplicated collection.

\section{Sample preparation and fluoride analysis}

2- $d$ duplicate plate. Duplicate food samples collected daily at home and school were pooled, weighed and homogenised using an industrial blender (Thermomix TM31; Vorwerk).

3-d food diary. Collected home-made food samples were also homogenised using a small domestic food processor (Kenwood CH180A; Kenwood).

The $\mathrm{F}$ concentrations of water and non-milk-based drinks were measured by a direct method and in triplicate using an F ion-selective electrode (F-ISE) (Model 9409; Orion) and meter (Model 720; Orion) after sample buffering with a total ionic strength adjustment buffer (TISAB III) ${ }^{(21)}$. Food samples and milk-based drinks were analysed in triplicate for F concentration after overnight hexamethyldisiloxane-facilitated diffusion at room temperature using an F-ISE and meter ${ }^{(21,22)}$. Reliability of the F measurements was checked by re-analysis of $10 \%$ of all food and drink samples, and a known amount of $\mathrm{F}$ was added to $10 \%$ of all the samples to evaluate the validity of the $\mathrm{F}$ analysis method.

\section{Assessment of daily dietary fluoride intake}

3-d food diary. The dietary records of each child were analysed using Weighed Intake Analysis Software Package (WISP) developed by Tinuviel, $\mathrm{UK}^{(23)}$. WISP is a nutritional analysis program based on nutrient files compiled from McCance and Widdowson's Food Composition Tables (5th and 6th Editions and their supplements) ${ }^{(24)}$. However, WISP, like any other nutrient software, does not include information on $\mathrm{F}$ content of food and drinks. An in-house F database developed by both Newcastle and Teesside Universities ${ }^{(25)}$ was used, from which information on the F content of several hundred food and drink items were added to WISP.

2- $d$ duplicate plate. Measured F concentrations of foods $(\mu \mathrm{g} / \mathrm{g})$, drinks and water $(\mu \mathrm{g} / \mathrm{ml})$ representing the average of triplicate readings were multiplied by the weight of the corresponding items consumed by each child per $d$ to estimate DDFI from each source.

\section{Statistical analysis}

Data were descriptively analysed using SPSS version 17.0 (SPSS), and a paired $t$ test was used to compare the two dietary methods at the group level.

Dietary data at the individual level were compared using linear regression analysis.

The typical within-child variability (expressed as a standard deviation) in dietary $\mathrm{F}$ intake from one measurement to the other was derived from the root of the mean square error for the within-subject effect.

\section{Results}

\section{Anthropometric data}

All sixty-one children completed all the aspects of the study. The mean age, weight, height and BMI were 5.5 ( $\mathrm{sD} 0.9$ ) years, $21.2(\mathrm{sD} 4 \cdot 1) \mathrm{kg}, 113 \cdot 1$ (SD $7 \cdot 3) \mathrm{cm}$ and $16 \cdot 4(\mathrm{sD} 1.9) \mathrm{kg} / \mathrm{m}^{2}$, respectively.

\section{Quality control of fluoride analysis}

The mean difference in $\mathrm{F}$ concentration from test to re-test ranged from $0.003 \mu \mathrm{g} / \mathrm{g}$ for food to $0.018 \mu \mathrm{g} / \mathrm{ml}$ for water samples. The mean percentage recovery of $\mathrm{F}$ added to the samples before $\mathrm{F}$ analysis was 99.3 (SD 0.53 ) \%.

\section{Comparison of the weight of consumed foods, drinks and water recorded using the two methods}

The mean weights of foods, drinks and water obtained by each method are presented in Table 1 . There was no statistically significant difference in the mean weight of consumed drinks (excluding water) between the two methods. However, the mean weight of collected water recorded by the 2-d DP method (204 g) was significantly higher $(P<0 \cdot 001)$ than the corresponding weight recorded by the $3-\mathrm{d}$ FD method ( $139 \mathrm{~g}$ ). For solid foods, the mean weight reported by the 3-d FD method $(839 \mathrm{~g})$ was significantly higher $(P<0.001)$ than that obtained by the 2-d DP method ( $734 \mathrm{~g})$. Overall, no statistically significant difference $(P=0 \cdot 88)$ was observed in the total weight of all foods and drinks consumed by the children between the 3-d FD (1271 g) and 2-d DP (1266 g) methods.

Comparison of daily dietary fluoride intake from foods, drinks and water using the two methods at the group level

The DDFI from three major dietary sources - food, drinks and water - recorded by each method are presented in Table 2 . The mean DDFI from drinks (excluding water) and from foods ( $\mathrm{mg} / \mathrm{d}$ and $\mathrm{mg} / \mathrm{kg}$ bw per $\mathrm{d}$ ) was not statistically significantly different between the two methods when analysed using a paired $t$ test. However, a statistically significantly higher DDFI from water $(P<0.001)$ was obtained when the 2 -d DP method was used. The mean DDFI from all dietary sources $(\mathrm{mg} / \mathrm{d}$ and $\mathrm{mg} / \mathrm{kg}$ bw per d) estimated by the 3-d FD method was 0.533 (sD 0.319$) \mathrm{mg} / \mathrm{d}(0.025$ (sD 0.016) $\mathrm{mg} / \mathrm{kg}$ bw per $\mathrm{d}$ ), whereas the 
Table 1. Comparing the mean estimated weight ( $\mathrm{g}$ ) of foods, drinks and water consumed, measured by 3-d food diary (3-d FD) and 2-d duplicate plate (2-d DP) methods

(Mean values and standard deviations; mean differences and $95 \%$ confidence intervals)

\begin{tabular}{|c|c|c|c|c|c|c|c|}
\hline \multirow[b]{3}{*}{ Source } & \multicolumn{7}{|c|}{ Weight (g) } \\
\hline & \multicolumn{2}{|c|}{ 3-d FD } & \multicolumn{2}{|c|}{ 2-d DP } & \multirow[b]{2}{*}{ Mean difference } & \multirow[b]{2}{*}{$95 \% \mathrm{Cl}$} & \multirow[b]{2}{*}{$P$} \\
\hline & Mean & SD & Mean & $\mathrm{SD}$ & & & \\
\hline Total drinks & 432 & 245 & 533 & 233 & -100 & $-151,-48$ & $0.001^{*}$ \\
\hline Water & 139 & 177 & 204 & 214 & -64 & $-97,-32$ & $0.001^{*}$ \\
\hline Other drinks & 293 & 255 & 329 & 219 & -35 & $-80,+9$ & $0.12 \dagger$ \\
\hline Foods & 839 & 233 & 734 & 193 & +105 & $+50,+160$ & $0.001^{*}$ \\
\hline Total & 1271 & 349 & 1266 & 311 & $+5 \cdot 25$ & $-66 \cdot 8,+77 \cdot 3$ & $0.88 \dagger$ \\
\hline
\end{tabular}

* Statistically significant.

† Not statistically significant.

Table 2. Comparison of mean fluoride $(F)$ intake from each dietary source $(\mathrm{mg} / \mathrm{d})$ and mean total daily dietary $\mathrm{F}$ intake (DDFI) estimated by 3-d food diary (3-d FD) and 2-d duplicate plate (2-d DP) methods (mg/d and $\mathrm{mg} / \mathrm{kg}$ body weight (bw) per d)

(Mean values and standard deviations; mean differences and $95 \%$ confidence intervals)

\begin{tabular}{|c|c|c|c|c|c|c|c|}
\hline \multirow[b]{3}{*}{ Source } & \multicolumn{4}{|c|}{ Dietary F intake } & \multirow[b]{3}{*}{ Mean difference } & \multirow[b]{3}{*}{$95 \% \mathrm{Cl}$} & \multirow[b]{3}{*}{$P$} \\
\hline & \multicolumn{2}{|c|}{ 3-d FD } & \multicolumn{2}{|c|}{ 2-d DP } & & & \\
\hline & Mean & SD & Mean & SD & & & \\
\hline \multicolumn{8}{|l|}{ DDFI (mg/d) } \\
\hline All drinks & 0.266 & 0.218 & 0.357 & 0.221 & -0.091 & $-0.140,-0.043$ & $0.001^{*}$ \\
\hline Water & 0.132 & 0.173 & 0.199 & 0.205 & -0.067 & $-0.099,-0.036$ & $0.001^{*}$ \\
\hline Other drinks & 0.134 & 0.194 & 0.158 & 0.173 & -0.024 & $-0.067,+0.019$ & $0.30 \dagger$ \\
\hline Food & 0.267 & 0.183 & 0.225 & 0.101 & +0.041 & $-0.001,+0.084$ & $0.06 \dagger$ \\
\hline \multicolumn{8}{|l|}{ Total DDFI } \\
\hline $\mathrm{mg} / \mathrm{d}$ & 0.533 & 0.319 & 0.583 & 0.263 & -0.050 & $-0.109,+0.009$ & $0.10 \dagger$ \\
\hline $\mathrm{mg} / \mathrm{kg}$ bw per d & 0.025 & 0.016 & 0.028 & 0.013 & -0.003 & $-0.006,+0.000$ & $0.10 \dagger$ \\
\hline
\end{tabular}

* Statistically significant.

† Not statistically significant.

Table 3. Comparison of within-child day-to-day variability in daily dietary fluoride intake (DDFI) (mg/d) estimated by each dietary method (Mean values and standard deviations; typical within-child variability and $95 \%$ confidence intervals)

\begin{tabular}{|c|c|c|c|c|c|c|c|c|}
\hline \multirow[b]{3}{*}{ Method } & \multicolumn{6}{|c|}{$\mathrm{DDFI}(\mathrm{mg} / \mathrm{d})$} & \multirow[b]{3}{*}{ Typical within-child variability } & \multirow[b]{3}{*}{$95 \% \mathrm{Cl}$} \\
\hline & \multicolumn{2}{|c|}{ Weekday (Day 1) } & \multicolumn{2}{|c|}{ Weekday (Day 2) } & \multicolumn{2}{|c|}{ Weekend day (Day 3) } & & \\
\hline & Mean & SD & Mean & SD & Mean & SD & & \\
\hline 3-d FD & 0.555 & 0.419 & 0.508 & 0.342 & 0.536 & 0.411 & $\pm 0 \cdot 280$ & $0.240,0.340$ \\
\hline 2-d DP & - & - & $0.574^{*}$ & 0.308 & 0.592 & 0.283 & $\pm 0 \cdot 191$ & $0.160,0.230$ \\
\hline
\end{tabular}

3-d FD, 3-d food diary; 2-d DP, 2-d duplicate plate.

* This is the 1st day of the 2-d DP method.

corresponding values estimated by the $2-\mathrm{d}$ DP method were not statistically significantly different at $0.583(\mathrm{sD} 0.263) \mathrm{mg} / \mathrm{d}(0.028$ (sD 0.013) $\mathrm{mg} / \mathrm{kg}$ bw per d).

\section{Comparison of daily dietary fluoride intake using the two methods at the individual level}

Based on the linear regression analysis, at the individual level, the typical error $(95 \% \mathrm{CI})$ in estimating $\mathrm{F}$ intake using the 3-d FD method compared with the 2-d DP method was within \pm 0.011 (95\% CI $0.009,0.013) \mathrm{mg} / \mathrm{kg}$ bw per d. Table 3 describes the higher within-child variation of $\pm 0.280(95 \% \mathrm{CI}$ $0 \cdot 240,0 \cdot 340) \mathrm{mg} / \mathrm{d}$ in DDFI when dietary data were collected using the 3-d FD method compared with the 2-d DP method, for which the within-child variation was $\pm 0 \cdot 191$ (95\% CI $0 \cdot 160$, 0.230) $\mathrm{mg} / \mathrm{d}$.

Comparison of the percentage of children with suggested optimal and tolerable upper intake level for fluoride intake using the two methods at the individual level

When dietary data were collected by the 3-d FD method, the DDFI of only $3.3 \%$ of the children was within the suggested optimal range for $\mathrm{F}$ intake (i.e. $0.05-0.07 \mathrm{mg} / \mathrm{kg}$ bw per d), whereas for $1.6 \%$ of the children the DDFI was higher than the threshold of the UL for $\mathrm{F}$ intake (i.e. $0.1 \mathrm{mg} / \mathrm{kg}$ bw per d). 


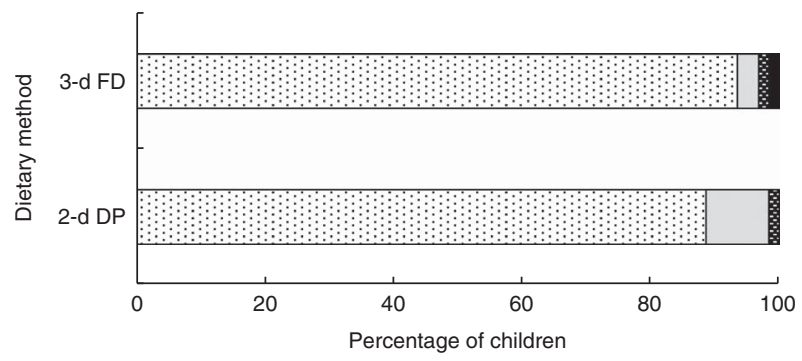

Fig. 1. Percentage of children with suggested suboptimal ( $\cdot<0.05 \mathrm{mg}$ fluoride (F)/kg body weight (bw) per d), optimal ( $\square, 0.05-0.07 \mathrm{mgF} / \mathrm{kg}$ bw per d), supraoptimal ( $\mathbf{R},>0.07$ to $<0.1 \mathrm{mgF} / \mathrm{kg}$ bw per d) and tolerable upper intake level of F intake ( $\square, \geq 0.1 \mathrm{mgF} / \mathrm{kg}$ bw per d) by the method of data collection - 3-d food diary (3-d FD) and 2-d duplicate plate (2-d DP).

However, when DDFI was estimated by the 2-d DP method, $9.8 \%$ of the children received optimal $\mathrm{F}$ intake and no child exceeded the UL for F intake (Fig. 1).

\section{Discussion}

This study compared DDFI recorded by the 3-d FD and 2-d DP methods at the group and individual levels and for the first time from the three major dietary groups: food, water and drinks. The selection of the number of data collection days for this study was mainly based on other $\mathrm{F}$ intake studies that used $2 \mathrm{~d}$ and $3 \mathrm{~d}$ for duplicate and food diary methods, respectively ${ }^{(11,12,26)}$. The present study showed no statistically significant differences in the estimated mean total weight of food and drinks consumed per $\mathrm{d}$ between the two methods (Table 1). Although the mean weight ( $\mathrm{g}$ ) of food consumed per $\mathrm{d}$ was lower when dietary data were collected by the 2-d DP method, this difference was not statistically significant. A possible explanation for the difference seen is the high level of co-operation required from participants while using the 2-d DP, as participants need to keep food containers with them for duplication of food and drinks consumed and/or purchase a similar portion of the food when they eat out. This is an extra cost and might result in participants altering their dietary habits, and therefore presents a problem with using this method, as such changes in dietary habits are not desirable in studies investigating customary nutrient intakes. The parents in the present study commented that they tended to change their customary dietary habits slightly (e.g. decided not to eat out) when duplicating meals (i.e. when using the 2-d DP method).

The 3-d FD method potentially offers several advantages, compared with the 2-d DP method, as it is cheaper with fewer burdens on the participants. Food diaries are pocket-sized and can be carried easily, allowing food and drink recordings to be made at the time of consumption, reducing the risk of omissions. The post-collection interview used with this method also enhances the accuracy of the methods by clarifying areas of potential misunderstanding by respondents as well as identifying omitted food and drinks. Furthermore, food and drink quantification is improved by the use of models of food and drink servings. As details of consumed food and drinks, including brand name, cooking and preparation methods and ingredients of mixed dishes, are recorded, the sources of $\mathrm{F}$ intake can also be identified more thoroughly and accurately ${ }^{(12)}$. It is not a common practice to collect food/drink items for analysis when assessing intakes of most nutrients using a food diary, as the Food Composition Tables provide information on the nutrient content of foods and drinks. However, in view of the impact of $\mathrm{F}$ concentration of the water used for preparation on the $\mathrm{F}$ content of a prepared meal, as well as the lack of $\mathrm{F}$ information in Food Composition Tables and reliance on an in-house $\mathrm{F}$ database ${ }^{(25)}$ for commonly consumed foods and drinks that requires regular updating, collection of home-made as well as school-made meals increased the precision of the food diary method when assessing dietary $\mathrm{F}$ intake.

In the present study, both the methods provided similar results for mean total DDFI at the group level. The majority of $\mathrm{F}$ intake studies have used a duplicate method to collect dietary data. The estimate for DDFI ( $\mathrm{mg} / \mathrm{kg}$ bw per $\mathrm{d})$ in the present study when a duplicate method was used was lower than the $0.040 \mathrm{mg} / \mathrm{kg}$ bw per d reported for 1.5-3-year-old children living in fluoridated areas of Indianapolis, USA ${ }^{(17,27)}$, and Piracicaba, Brazil $^{(28)}$ and for 4-6-year-old children living in optimally fluoridated Bauru, Brazil ${ }^{(29)}$. However, it was higher than 0.019 and $0.018 \mathrm{mg} / \mathrm{kg}$ bw per $\mathrm{d}$ reported for 3-4-year-old and 4-7-year-old children living in water fluoridated communities of New Zealand ${ }^{(11)}$ and Brazil ${ }^{(28,30)}$. Conversely, for another group of 1-3-year-old Brazilian children living in fluoridated Ibia and Bauru $^{(6,28)}$, the reported DDFI of 0.027 and $0.025 \mathrm{mg} / \mathrm{kg}$ bw per $\mathrm{d}$, respectively, were close to the findings of the present study.

The present study's estimate for DDFI when the 3-d FD method was used can be compared with those reported for UK and Iranian children, as those studies also used a food diary method to collect dietary data ${ }^{(12,30)}$. The DDFI for children in the present study at $0.025 \mathrm{mg} / \mathrm{kg}$ bw per $\mathrm{d}$ was similar to that reported for 6-7-year-old UK children ${ }^{(12)}$, but was lower than the $0.049 \mathrm{mg} / \mathrm{kg}$ bw per $\mathrm{d}$ reported for 4-year-old Iranian children $^{(18)}$. Within these studies that used the same dietary methods, differences in the preparation of food as well as in dietary habits could have contributed to the differences in DDFI. Between those studies that have used different dietary methods, discrepancies in DDFI could also be attributed to the use of different dietary data collection methods.

A recent study in the $\mathrm{USA}^{(17)}$ used and compared the same two dietary methods used in this study on a group of 15-30-month-old children. The mean DDFI of 0.038 (sD 0.011) and $0.040(\mathrm{SD} 0.016) \mathrm{mg} / \mathrm{kg}$ bw per d obtained when dietary data were collected by food diary and duplicate plate methods, respectively, were higher than the corresponding values obtained in the present study. Age differences between the American children and those from the present study could have contributed to the difference in DDFI, as dietary habits/ consumption patterns of children vary depending on age. In addition, the actual $\mathrm{F}$ content of food and drinks consumed by the US children might have been higher. Based on the individual dietary sources, the present study found a similar F intake from food between the two methods, whereas in the US study a higher $\mathrm{F}$ intake from food was reported when the food diary method was used $-0.188 \mathrm{mg} / \mathrm{d}$ compared with $0.130 \mathrm{mg} / \mathrm{d}$ 
reported for the duplicate plate method. In the present study, a statistically significantly higher $\mathrm{F}$ intake from all drinks including water was observed when using the 2-d DP method, whereas for the US children no statistically significant difference in DDFI from drinks was reported between the two methods. Higher $F$ intakes from water have been reported for Iranian ${ }^{(18)}$ and Brazilian $^{(29)}$ children due to increased air temperatures during summer; however, drinks consumption of the children in the present study was not affected by seasonal temperature because in north-east England, where the data collection was performed, seasonal temperature variation is low. During data collection, between April and November, the mean annual temperature was $9^{\circ} \mathrm{C}$ ranging from $2^{\circ} \mathrm{C}$ in December to $16^{\circ} \mathrm{C}$ in August $^{(31)}$.

In this study, the lack of a statistically significant difference in the mean DDFI estimated by the 3-d FD and 2-d DP methods at the group level suggests that either method can be used at the population level to estimate DDFI. There are many potential sources of errors in any dietary assessment method, and although these may cancel each other out at the group level, they might introduce a large source of error at the individual level. To investigate this, the agreement between the methods at the individual level was also examined using linear regression analysis. The use of linear regression in preference to the Bland-Altman method ${ }^{(32)}$ in the present study was mainly due to the proportional bias that was observed in the Bland-Altman plot and it was not removed after log transformation of the data. Based on regression analysis, at an individual level, the agreement in estimating $\mathrm{F}$ intake $(\mathrm{mg} / \mathrm{kg}$ bw per $\mathrm{d}$ ) using the 3-d FD method compared with the 2-d DP method was within $\pm 0 \cdot 011(95 \%$ CI $0 \cdot 009,0 \cdot 013) \mathrm{mg} / \mathrm{kg}$ bw per $\mathrm{d}$.

This typical error, although small, may put individuals in a different $\mathrm{F}$ intake category due to the narrow margin between the suggested optimal and excessive $\mathrm{F}$ intakes, as observed in the present study (Fig. 1). This is particularly important when a study aims to determine the percentage of children with optimal, suboptimal or excess $\mathrm{F}$ intakes in order to plan a communitybased fluoridation scheme. These findings suggest that DDFI data obtained by one of these dietary methods cannot replace those obtained by the other method when individual intakes are compared.

Some authors have suggested ${ }^{(17)}$ and/or used both methods ${ }^{(11,33)}$ in their studies in order to check the validity of collected duplicate diets. Although this approach might enhance the reliability of duplicated dietary data, the feasibility of such an approach should be considered carefully as it creates extra work for the participants, which may affect the compliance rate and the tendency to under-report. In addition, the use of both methods alongside each other in large-scale studies might not be practical and the feasibility of this approach would benefit from further investigation.

Generally, none of the dietary assessment tools have been validated and/or calibrated for measurement of dietary F intake in any population. Therefore, validation and calibration studies are required to develop a universal standardised dietary assessment method to assess dietary $\mathrm{F}$ intake over time within a population as well as to compare population $\mathrm{F}$ intakes and body burden between countries. Among different dietary assessment methods, the 7-d weighed food diary, referred to as the 'gold standard' method ${ }^{(10)}$, has been used for calibration studies. However, validation studies have usually used 24-h urine as a biomarker to compare intake of a nutrient assessed from a dietary method against levels estimated from urine samples.

The reliability analysis showed a greater typical day-to-day within-child variation with the 3-d FD method compared with the 2-d DP method. Within-child variation in F intake for the US children was also reported to be higher when the food diary method was used. However, the extent of within-child variation in DDFI was smaller than the variation found in this study. This could be due to recruiting children from a single day-care centre with identical food menus and limited choice of food, whereas in the present study variation in food types was greater as the majority of children had their own packed lunch and also the possibility of swapping their food/snacks with friends. The other possibility that may have contributed to a smaller variation in DDFI seen in the US children is that dietary data for those children were only collected on weekdays, which, according to the authors, was done to avoid variations in diet during weekends. In contrast, in the present study, dietary data collection covered both weekdays and weekend days.

Greater within-child variation in DDFI found when the food diary method was used also suggests an ability of this method to capture more variations compared with the duplicate method. This could be due to a more detailed recording of consumed food and drinks, although it should be noted that recalling such detail can sometimes be difficult for participants, resulting in researchers being tempted to use assumptions.

\section{Conclusion}

At the group level, either of the two dietary methods (2-d DP or $3-\mathrm{d}$ FD) is suitable for estimating DDFI. However, at an individual level, due to the narrow margin between optimal and excessive F intake, DDFI data obtained by one of these methods cannot replace those data estimated from the other method during the same data collection period. A validated standardised dietary assessment method is needed to monitor dietary F intake over time and also enable multi-country comparisons.

\section{Acknowledgements}

The authors thank the schools and parents for their invaluable assistance during data/sample collection.

This study was supported by grants from Teesside University Research Doctoral Scholarships and The Borrow Foundation.

N. O. and F. V. Z. designed the research. N. O. collected the information and samples and analysed the samples and data. N. O., F. V. Z., A. M. and W. T. O' H. were involved in manuscript drafting. All the authors read and approved the final version of the manuscript. Sample preparation and analysis was carried out in the School of Dental Sciences and School of Science and Engineering at Newcastle and Teesside Universities, respectively, and Newtec Food Laboratory, Billingham.

The authors have no conflicts of interest to disclose. 


\section{References}

1. Palmer C \& Wolfe S (2005) Position of the American Dietetic Association: the impact of fluoride on health. $J$ Am Diet Assoc 105, 1620-1628.

2. Featherstone JDB (1999) Prevention and reversal of dental caries: role of low level fluoride. Community Dent Oral Epidemiol 27, 31-40.

3. McDonagh MS, Whiting PF, Wilson PM, et al. (2000) Systematic review of water fluoridation. BMJ 321, 855-859.

4. Burt BA (1992) The changing patterns of systemic fluoride intake. J Dent Res 71, 1228-1237.

5. Institute of Medicine (1999) Dietary Reference Intakes for Calcium, Magnesium, Vitamin D, and Fluoride. Washington, DC: National Academies Press.

6. de Almeida BS, da Silva Cardoso VE \& Buzalaf MA (2007) Fluoride ingestion from toothpaste and diet in 1-to 3-year-old Brazilian children. Community Dent Oral Epidemiol 35, 53-63.

7. Levy SM, Warren JJ \& Broffitt B (2003) Patterns of fluoride intake from 36 to 72 months of age. J Public Health Dent 63 , 211-220.

8. Zohoori FV, Walls R, Teasdale L, et al. (2013) Fractional urinary fluoride excretion of 6-7-year-old children attending schools in low-fluoride and naturally fluoridated areas in the UK. Br J Nutr 109, 1903-1909.

9. Zohouri FV, Maguire A \& Moynihan PJ. (2006) Sources of dietary fluoride intake in 6-7-year-old English children receiving optimally, sub-optimally, and non-fluoridated water. J Public Health Dent 66, 227-234.

10. Willett W (1998) Nutritional Epidemiology. New York: Oxford University Press.

11. Guha-Chowdhury N, Drummond BK \& Smillie AC (1996) Total fluoride intake in children aged 3 to 4 years - a longitudinal study. J Dent Res 75, 1451-1457.

12. Maguire A, Zohouri FV, Hindmarch PN, et al. (2007) Fluoride intake and urinary excretion in 6-to 7-year-old children living in optimally, sub-optimally and non-fluoridated areas. Community Dent Oral Epidemiol 35, 479-488.

13. Basiotis PP, Welsh SO, Cronin FJ, et al. (1987) Number of days of food intake records required to estimate individual and group nutrient intakes with defined confidence. J Nutr 117, $1638-1641$.

14. Gibson R (2005) Principles of Nutritional Assessment. New York: Oxford University Press.

15. Petersen P, Baez R \& Marthaler T (2014) Basic Methods for Assessment of Renal Fluoride Excretion in Community Prevention Programmes for Oral Health. Geneva: WHO.

16. Marthaler TM (1999) Monitoring of Renal Fluoride Excretion in Community Preventive Programmes on Oral Health. Geneva: WHO.
17. Martinez-Mier EA, Kelly SA, Eckert GJ, et al. (2009) Comparison of a dietary survey and the duplicate plate method for determining dietary fluoride ingested by young children: a pilot study. Int J Paediatr Dent 19, 99-107.

18. Zohouri FV \& Rugg-Gunn AJ (2000) Sources of dietary fluoride intake in 4-year old children residing in low, medium, and high fluoride areas in Iran. Int J Food Sci Nutr 51, 317-326.

19. Nelson M, Atkinson M \& Meyer J. (1997) A Photographic Atlas of Food Portion Sizes. London: Ministry of Agriculture, Fisheries and Food.

20. Chowdhury N (1990) Fluoride intake of infants in New Zealand. J Dent Res 69, 1828-1833.

21. Martinez-Mier EA, Cury JA, Heilman JR, et al. (2011) Development of gold standard ion-selective electrode-based methods for fluoride analysis. Caries Res 45, 3-12.

22. Taves DR (1968) Separation of fluoride by rapid diffusion using hexamethyldisiloxane. Talanta 15, 969-974.

23. Weighed Intake Analysis Software Package (2006) Version 3, Intakes, Recipes and Menu Analysis. UK: Tinuviel Software.

24. McCance R, Widdowson EM \& Holland B (1991) McCance and Widdowson's the Composition of Foods, 5th ed. Cambridge, UK: The Royal Society of Chemistry and Ministry of Agriculture Fisheries and Food.

25. Zohoori FV \& Maguire A (2014) Database of the Fluoride (F) content of Selected Drinks and Foods in the UK. UK: Newcastle University \& Teesside University.

26. Zohouri FV \& Rugg-Gunn AJ (2000) Total fluoride intake and urinary excretion in 4-year-old Iranian children residing in low-fluoride areas. Br J Nutr 83, 15-25.

27. Rojas-Sanchez F, Kelly SA, Drake KM, et al. (1999) Fluoride intake from foods, beverages and dentifrice by young children in communities with negligibly and optimally fluoridated water: a pilot study. Community Dent Oral Epidemiol 27, 288-297.

28. Paiva SM, Lima YBO \& Cury JA (2003) Fluoride intake by Brazilian children from two communities with fluoridated water. Community Dent Oral Epidemiol 31, 184-191.

29. Rodrigues MHC, Leite AL, Arana A, et al. (2009) Dietary fluoride intake by children receiving different sources of systemic fluoride. J Dent Res $\mathbf{8 8}, 142-145$.

30. Pessan JP, de Silva SMB \& Buzaluf MAR (2003) Evaluation of the total fluoride intake of 4-6 year old children from diet and dentifrice. J Appl Oral Sci 11, 150-156.

31. Met Office UK (2009) England Mean Temperature. http:// www.metoffice.gov.uk/climate/uk/2009/ (accessed June 2013).

32. Bland JM \& Altman DG (1986) Statistical methods for assessing agreement between two methods of clinical measurement. Lancet 327, 307-310.

33. Haftenberger M, Viergutz G, Neumeister V, et al. (2001) Total fluoride intake and urinary excretion in German children aged 3-6 years. Caries Res 35, 451-457. 